\title{
Higher Education and Quality Assurance in Egypt: Pre and Post COVID19
}

\author{
Sameerah Tawfeeq Saeed ${ }^{1}$ \\ ${ }^{1}$ English Language Teaching Department, Faculty of Education, Tishk International University, Erbil, \\ Iraq \\ Correspondence: Sameerah Tawfeeq Saeed, Tishk International University, Erbil, Iraq. \\ Email: samira.saeed@tiu.edu.iq; saeedors@gmail.com
}

Doi: 10.23918/ijsses.v8i2p96

\begin{abstract}
This paper presents an overview of the higher education and quality assurance systems in the Arab Republic of Egypt. Egypt is known for its prosperous history in the field of education and higher education dating back to 5000 years ago. The system of higher education has undergone considerable changes and improvements since then. The introduction of the quality assurance system in 2000 and the establishment of the National Agency of Quality Assurance and Accreditation of Education (NAQAAE) in 2006 well attest that. This paper provides a descriptive account of the history, structure and main properties of the higher education system and quality assurance in pre and post COVID19 in the country. The data presented reveals abundant promise in the evolution of the higher education system in Egypt, especially in its ability to own an accreditation body that offers accreditation certificates at a national level. Moreover, Egypt is making thoughtful steps towards digitalization especially with the implementation of the blended education imposed due to the COVID19 pandemic.
\end{abstract}

Keywords: Higher Education, Quality Assurance, Egypt, Blended Education, COVID19, Accreditation

\section{Introduction}

The country of pyramids, Egypt, has emerged from Nile Valley in the $31^{\text {st }}$ century BC and is therefore considered one of the world's first civilizations. The Arab republic of Egypt is the largest Arab state by population (estimated at 100 million citizens in 2021) ${ }^{1}$ that spreads over the southeastern corner of the Mediterranean, enjoying a strategic geographic location linking Middle East, Africa, and Europe. "It is rich in natural resources, with the oil and gas sector making up approximately 15 percent of the country's gross domestic product (GDP)" (Ibara et al., 2019, p. 2). Throughout history the state has experienced major political changes and economic growths as well as crises, most notably since 2011. These fluctuations have, consequently, affected all aspects of life including health and education sectors which have witnessed several changes and reforms.

Received: April 25, 2021

Accepted: June 8, 2021

Saeed, S.T. (2021). Higher Education and Quality Assurance in Egypt: Pre and Post COVID19. International Journal of Social Sciences \& Educational Studies, 8(2), 96-107.

\footnotetext{
${ }^{1}$ This population is based on World meters elaboration of the latest United Nations data as of March 12, 2021: https://www.worldometers.info/world-population/egypt-population/
} 
In Egypt, education has long been a high priority and one of the top agenda of the ruling system throughout years. 'Oan' (Sun/Heliopolis) University (established 5000 years ago), Alexandria Library (established about 250 BC) and Al-Azhar University (established in 970 AD) are reminiscent examples of very earlier Egyptian's education interests. Up until 1962, education was limited to a select group of high social classes who could afford the high tuition fees. Today, in twenty-first century, higher education institutions (public and private) in Egypt are available for all social categories under the supervision of the Ministry of Higher Education and Scientific research, established in 1961. The publics are divided into public universities (27), technical faculties (46) and Al-Azhar University, while privates include private universities (23) and private (higher and middle) institutes (168) (retrieved on April 1st 2021 from the Ministry's website http://portal.mohesr.gov.eg/ar-eg/Pages/default.aspx).

The beginning of quality assurance initiations and practices goes back to after the National Conference on Higher Education Reform held in 2000. Today, quality assurance is actually a subject taught at universities in Egypt to spread the culture of quality and be deeply rooted in the education system. Moreover, in Egypt there is the National Authority of Quality Assurance and Accreditation (NAQAAE) which grants national accreditation to its higher education institutions (HEIs).

In this paper, a sound overview of the structure, policy, and regulations of higher education in the Arab Republic of Egypt shall be offered, most particularly in terms of the quality assurance system before and after COVID19. The method applied in this study is a desk-based analytical research of the existing literature on the higher education and quality assurance system in Egypt. The literature sources that were reviewed included research papers, books, policy documents, guideline handbooks and reports published on the website of Ministry of Higher Education and NAQAAE. Moreover, semi-structured interviews have been conducted with a few staff and officials at Universities and NAQAAE.

The rest of the paper is organized as follows. Section 2 presents a brief history and overview of Egyptian higher education system. In section 3, details about the Egyptian quality assurance process and procedures in higher education are elaborated, along with an overview of its national accreditation system represented by NAQAAE. The blended education system introduced post COVID19 is the focus of section 4. A conclusion is given in section 5 .

\section{Egyptian Higher Education System}

\subsection{A Brief History}

The Higher Education system in Egypt went through a number of eras affected mainly by the political and ruling system therein dating back to 5000 years ago when 'Oan' University was built in ancient Egypt. Some of the famous graduates of this University were Amenhotep and Akhenaten, the most famous pharaohs of the Ancient Egypt (Shann, 1992; Radwan, 2016; Emira, 2014). Egypt is also known for the world's oldest university that is still operating, Al-Azhar University, which was founded by the Fatimids in the tenth century (Reid, 1990, p. 11). Al-Azhar University, supervised by the Ministry of Al-Azhar Affairs, is known for its mainstream religious education providing courses that focus on Islamic studies, Islamic law, Arabic Grammar and Jurisprudence. 
Egypt's state system of education has started in the 1820s as part of Muhammed Ali Pasha's, Viceroy of Egypt (1805-1849), plan to establish a modern Egypt with a secular education. The first state university in modern Egypt was established in 1908, named the Egyptian University, and later in 1940 was called King Fuad I University following the name of the King of Egypt. After the 1952 revolution, the University was renamed and became the present Cairo University (Reid, 1990; Richards, 1992; Farag, 2007). Most of its students were graduates of the high schools or Al-Azhar schools who could afford the high education expenses. A prominent postgraduate of Cairo University was Taha Hussein, one of the most influential Egyptian figures in modern Arabic literature in the twentieth century.

In addition, the American University, a private university, was established in 1919 by a group of American educators who were keen to spread the American culture in the Middle East and present a liberal arts education. The first programs offered were arts, science, education, and oriental studies, and until 1928 the institution was limited to males (see full history in https://www.aucegypt.edu/about/history). It is the oldest private university in Egypt and today it is ranked among the top universities in the country ${ }^{2}$. Furthermore, in the mid of the twentieth century and due to increase of high schools graduates and outgrow of higher education interest, two other universities were established by the government: Alexandria University (originally known as Farouk University) in Alexandria in 1942 and Ain Shams University in Cairo in 1950. In the 1970s several other universities were established, such as the University of Tanta and University of Mansoura in 1972, University of Zagazig in 1974, University of Helwan in 1975, and University of Menia, University of Menoufia and Suez Canal University in 1976 (see Shann, 1992, p. 227).

\subsection{Modern Organization}

Today, 2021, in Egypt, higher education system is offered through a set of institutions that include universities, technical colleges, higher specialized institutes, middle and upper middle institutes and academies. The laws that govern and regulate higher education therein are: (a) Law on Regulation of Universities (Law no. 49-1972); (b) Law on Regulation of Private Universities (Law no. 101-1992); and (c) Law on Regulation of Private and National (Non-profit) Universities (Law no. 12-2009). Within the Ministry of Higher Education three main supreme councils operate that are in charge of public and private higher education in Egypt. The public higher education system and institutions are supervised by the Supreme Council of Universities (SCU), established in 1954. Private universities are licensed and regulated by the Supreme Council of Private Universities (SCPU), established in 2002 by a Presidential Decree. The third council is the Supreme Council for Technical Education and Vocational Training, which supervises technical institutions and vocational education and training (see Radwan, 2016, pp.16-18).

A regulatory framework is in place to control the minimum requirements for the establishment of new higher education institutions in Egypt; these include qualification and number of academic staff, curricular,

\footnotetext{
2 See the Ranking Web of Universities http://www.webometrics.info/en/Africa/Egypt and the World Universities Ranking https://worldtop20.org/globaluniversities?gclid=EAIaIQobChMI3rnXg5T55QIVgeJ3Ch1GLQK2EAAYASAAEgLfUvD_BwE
} 
infrastructure and facilities (OECD/the World Bank, 2010). Moreover, similar to public universities, private ones should also be accredited through NAQAAE.

The universities offer four- or five-year programs in a variety of major fields that include faculties or colleges and grant baccalaureate degree. Technical faculties offer again four- or five-year programs and grant baccalaureate degrees similar to universities. Higher and lower institutes offer two-year programs in diverse technical areas and grant a technical diploma. Postgraduate diplomas (one- or two-year) and postgraduate degrees (master and doctoral) are also offered at universities.

The number of students enrolled in Egyptian higher education institutions has reached 3 million in 20182019 with an increase of 4\% compared to 2017-2018. The percentage of students enrolled in public universities and Al-Azhar University highly surpasses those enrolled in the private universities. For instance, the rate during 2018-2019 was 72.9\% (public and Al-Azhar) comparing to 6.3\% (private) (Retrieved on January 15, 2020, from http://www.capmas.gov.eg/).

In terms of financing, public institutions are centralized and funded by the government processed by Ministry of Finance through Ministry of Higher Education. Their autonomy is, therefore; restricted and bounded mainly by available budgets and approval of the Ministry of Higher Education. However, very small tuition fees are imposed by some departments/faculties and approved by the Supreme Council of Universities. These fees-based public degrees have been initiated in 2007 to meet market needs. Private institutions are self-funding and mostly for-profit ones relying mainly on tuition fees. Private universities enjoy financial independence and can decide on their own resources and research funds (Buckner, 2013).

The Egyptian higher education, since the 21 st century, has been aiming to respond to "the current and future needs of social development, job market, and production" (Ramadan, Zaaba, \& Umemoto, 2011, 341). Egypt's higher education strategic objectives, in light of the sustainable development plan of Egypt vision 2030, include providing education to all without discrimination; improving the quality of education system that is in line with international systems; improving the competitiveness of education system and outputs; and establishing campuses of international universities (retrieved on January 15, 2021 from the Ministry of Higher Education website http://portal.mohesr.gov.eg/en-us/Pages/default.aspx in January 2020). Many projects and activities have been planned and implemented to achieve the objectives set: new public and private universities as well as technological universities are established especially in the underserved areas, new research centers established, a special committee for accrediting technical education has been established by the Supreme Council of Universities, curriculum renewal in the field of medicine, education and engineering are developed, included in several international rankings such as Times Higher Education World University Rankings, QS Ranking and Shanghai Ranking, and several Memorandums of Understanding have been signed with international universities to open their campuses in Egypt and organize joint educational and research programs.

\subsection{Development of Higher Education}

The higher education process in Egypt witnessed an enormous transfer post the National Conference of Higher Education in 2000 which led to a long-term higher education development and reform plan. Following the conference 25 projects were initiated and planned under the guidance of Ministry of Higher 
Education for 2000-2017, out of which 6 projects have been prioritized in the reform: Faculty and Leadership Development Project (FLDP), Information and Communication Technology Project (ICTP), Quality Assurance and Accreditation Project (QAAP), Faculty of Education Project (FOEP), Enhancement of Technical Colleges Projects (ETCP) and Higher Education Enhancement Projects (HEEP). Funds for these projects were provided from the Egyptian government in coordination with the International Bank for Reconstruction and Development (IBRD) (see Radwan, 2016, pp. 24-26).

The reform in higher education was triggered by the government's realization of its need to support and enhance the educational, economic, and social progress of the country on a national and international basis. The HE strategic reform included six projects: Reform of Faculties of Education Project, Restructuring Middle Technical Institutes Project, Faculty Development and Leadership Development Project, Information and Communication Technology related projects, Higher Education Enhancement Project Fund, and Quality Assurance and Accreditation Project. However, despite the substantial efforts made by the government to improve higher education processes, the OECD/World Bank (2010, p. 14) has recommended more attention to be paid to structural reform rather than procedural reform by "changing the institutional culture and increasing the capacity of the system to contribute to the realization of national goals".

For the higher education reform of Egypt ten main directions have been recommended in the OECD/World Bank's (2010) report: clarifying the expected capabilities of graduates, improving the balance of graduate output to fit labor market needs, strengthening national steering capacity, diversifying the supply of higher education opportunities to meet a larger student body with varying needs, aptitudes and motivations, increasing institutional operating flexibility and self-management capacity, sharing costs more equitably between the Egyptian government and general taxpayers, widening admission criteria to recognize diverse potential, raising input quality and embedding quality assurance as an institutional responsibility, strengthening university research capacity and its links to innovation, and building a number of leading exemplars.

\section{HE Quality Assurance in Egypt}

\subsection{Emergence and Evolution}

The process of quality assurance in higher education in Egypt has started with the formation of the National Committee of the Quality Assurance and Accreditation Project (QAAP), one of the strategic reform priority projects initiated during the first phase (2002-2007) of the reform process of higher education in Egypt. The main mission of the project was to assure the community of the performance and quality of the higher education institutions in Egypt. This was to be achieved through applying accredited standards, employing professional human resources, and providing sufficient budget. Earlier to this start was the establishment of an internal quality assurance system at HEIs in 2000 following the National Conference for Higher Education in 2000. The need for the quality assurance scheme was triggered by the decline in quality due to the vast expansion of higher education institutions during 1970-2000.

QAAP aimed primarily at disseminating the culture of quality in the higher education institutions in Egypt; introducing and developing the quality assurance and accreditation policy and procedures; enhancing the 
quality of higher education; and preparing qualified graduates able to meet the needs and expectations of the market. The initiation of the quality assurance and accreditation process was supported by grants and loans from the International Bank for Reconstruction and Development (IBRD), made available through the Higher Education Enhancement Project (HEEP) (Ramadan, Zaaba \& Umemoto 2011, 342). HEEP led to twenty-five projects that addressed a variety of higher education areas and implemented in three phases as mentioned above.

In the period 2002-2007, the higher education system in Egypt witnessed a tremendous change in the quality assurance process: establishment of internal quality assurance systems at universities; implementation of specific quality assurance procedures and documented practices; increase of the awareness of faculty members about quality assurance concepts, standards and objectives through the several workshops and trainings organized; and establishment of quality assurance units and quality assurance centers at public universities. In addition, preparation towards the establishment of the National Authority for Quality Assurance and Accreditation of Education (NAQAAE) was made in terms of its bylaws and standards needed for the institutional and program accreditation as well as training staff and reviewers; NAQAAE is a national body that is responsible for the quality offered at the higher education institutions and accrediting them on a national basis (details about NAQAAE are given in 3.3).

In the second phase of the reform process, (2007-2013), the Program of Continuous Improvement and Qualifying for Accreditation (PCIQA) has been introduced and aimed at enabling public HEIs to carry out continuous improvement, upgrading their quality assurance systems to meet high academic and institutional standards and preparing them for accreditation. To achieve these, PCIQA was allocated a budget through the Egyptian government to fund mainly 7 projects: the Quality Assurance and Accreditation Project 2 (QAAP2); the Continuous Improvement and Qualification for Accreditation Project (CIQAP); the Development Academic Programs for Accreditation Project (DAPAP); Higher Education Institutions' Labs Accreditation Project (HLAP); Development of Student Assessment Systems Project (DSASP); Infrastructural Quality Related Projects (IQRP); and Monitoring and Evaluation of New Programs Project (MENPP). Based on the fund provided, faculties and universities have been encouraged to submit projects reviewed and evaluated attentively by the steering committee of PCIQA according to a set of criteria that consider the proposed project's academic excellence, technical quality, efficiency, sustainability, cooperation and multi-disciplinary aspect, creativity, and contribution to accreditation (Ramadan, Zaaba \& Umemoto 2011, 344). By the end of 2011, PCIQA funded up to 396 projects in 260 public HEIs (Radwan, Sharaf, \& Ibrahim 2015, p. 4). After 2013, till today, work has continued to update standards and procedures of the internal quality assurance system at all HEIs, public and private, as well as those of NAQAAE that serve upgrading the higher education system of the country.

Today, in the first year at almost all universities in Egypt, a course called 'introduction to quality education' is taught. The course introduces the concept of quality assurance and an overview of NAQAAE. It helps to disseminate the concept and culture of quality among students and hence the whole society. The course involves pass/fail system through a written based exam and part of the assignments includes students' presentations at schools and other universities or faculties supervised by teachers. 


\subsection{Internal and External Quality Assurance System}

The internal quality assurance system includes quality assurance units in colleges and institutes, quality assurance centers at $\mathrm{HE}$ institutions and Program of Continuous Improvement and Qualifying for Accreditation (PCIQA), all supported financially by the Ministry of Higher Education. Each of these has its own features and functions that target the quality assurance and quality enhancement processes. For instance, quality assurance units help disseminate quality culture among faculty members, maintain the implementation of required quality procedures such as student feedback, course and program assessment and self-assessment of the institution in terms of documentation, accuracy and systematicity. Quality assurance units are supported by quality assurance centers which help the HEIs to be qualified for accreditation.

Establishing an internal quality assurance system in public universities was one the steps taken up and funded by QAAP. The latter was organized through a number of monitoring committees who monitored and evaluated the process of internal quality system in the academic institutions. Among the evaluative criteria were:

a- the academic standards of the program, including: the targeted learning outcomes, criteria, student assessment, and student achievement; b- quality of learning opportunities, which include teaching and learning, student support and learning resources; c- research and scholarly activities; d- community and environmental services; e- the effectiveness of quality management and enhancement (Ramadan, Zaaba, \& Umemoto 2011, p. 340).

All public and private HEIs in Egypt are required to develop their internal quality assurance systems and among the main policies and procedures that should be developed are course specifications, program specifications, periodic strategic reviews, student feedback, class observation and annual self-evaluation reports. These quality assurance practices formed the bases of traditional education taking place in campus. However, with the introduction of online education process imposed on higher education institutions as a response to the lockdown caused by COVID19 pandemic, new practices and procedures have been developed and introduced as a response. This will be further discussed in section 4 .

As for practices of external quality assessment, pre university and higher education institutions have been encouraged to obtain accredited status which will help improve the quality of education and academic standards of the institution and its programs. This will enable the institutions in Egypt to compete internationally through presenting high quality of education and be eligible to achieve international accreditation. Part of the quality assurance scheme called for the establishment of a national body that is responsible for the quality offered at the higher education institutions and accrediting them on a national basis. The result was the establishment of NAQAAE in 2006. See the discussion in the next section.

Another external assessment encouraged at the educational institutions in Egypt is benchmarking which involves comparison of national standards to equivalent international ones. This process is found challenging for most institutions in Egypt due to lack of national standards. However, the National Quality Assurance and Accreditation Agency (NQAAA) and the Supreme Council of Universities in Egypt have worked on developing national reference standards for higher education to consider as part of the 
benchmarking process (see the National Quality Assurance and Accreditation Committee and the British Consultants in Higher Education 2004).

\subsection{NAQAAE}

NAQAAE, the National Authority for Quality Assurance and Accreditation of Education, was established in 2006 as a result of the national plan to reform education in Egypt. This has followed the national conference of education reform in 2000. NAQAAE's function was initiated in 2007 by the presidential Act 25 as an independent government agency supervised by the Prime Minister's office. The Agency is responsible for the accreditation of higher education institutions, technical and vocational education training and pre university education, as well as the coordination and development of the National Qualifications Framework in Egypt. A board of directors with stakeholder representation forms the governance of the agency, while assessments and audits are performed by trained assessors. NAQAAE envisions to become an internationally recognized accreditation agency known for its credibility and objectivity and able to develop itself to ensure the quality of education and achieve excellence (NAQAAE 2015: 8). In addition, NAQAAE is accredited by the World Federation of Medicine Education (WFME). The mission of NAQAAE is.

"To ensure quality, continuous development and efficient performance of Egyptian higher education institutions, of their systems and of their programmes, in accordance with their mission statements and declared goals; and to gain the confidence of the community in their graduates, depending on distinguished and competent human resources, and based on internationally recognized evaluation mechanisms through an independent, neutral and transparent framework" (The National Quality Assurance and Accreditation Committee in Collaboration with British Consultants in Higher Education, 2004, p. 7).

The main purposes set by NAQAAE include achieving total quality assurance and continuous development of education in line with the national development schemes; supporting and enhancing education institutions in the processes of knowledge building, skill development, research publication and community service; maximizing the return on investment in education to increase the national product and considering it as one of the channels of increasing the national income; and gaining trust and support of the community and its various institutions (NAQAAE 2015, pp. 8-9).

In order for an educational institution to be accredited by NAQAAE, a number of conditions are required to be qualified initially. These are: the institution should be licensed by Ministry of Higher Education; one of the academic programs should have completed its cycle and have graduates; the institution has a strategic planning, internal audit systems and annual reports; it has a formal administrative council; it has a specific recognized and announced mission; and finally, the institution has to gain approval of the official body it belongs to in order to apply for accreditation. It is worth noting that universities in Egypt have the liberty to obtain international accreditations, but it is obligatory to obtain the national accreditation through NAQAAE. These were confirmed through an interview with Dr. Maha Rashwan, a staff member in the technical bureau at NAQAAE on October 16, 2019. She also added that NAQAAE consists of 9 academic and technical staff, while the reviewers are composed of external staff. Dr. Rashwan highlighted the significant role the process of quality assurance and accreditation have had on the performance of teaching 
staff. Prior to the introduction of quality assurance, the staff used to complete their daily commitments merely, but at the present more enthusiasm is noticed among staff. In addition, studies are planned to examine the impact of quality assurance and enhancement on teaching, learning and research at the Egyptian universities.

For institutional accreditation, twelve criteria are considered: strategic planning, leadership and governance, quality management and development, faculty members and assisting staff, administrative agency, financial resources and technical infrastructure, academic criteria and teaching and learning, students and alumni, scientific research and activities, postgraduate studies, and community participation and environmental development (NAQAAE 2015, pp. 29-30). Each of these criteria is defined according to a set of indicators against which the assessment process of accreditation is practiced. These criteria have been developed from early assessment of some institutions and reflect best practices at the national and international level.

The accreditation process for higher education institutions is initiated with a self-report submitted by the institution. The report is reviewed by a team of peer reviewers assigned by NAQAAE (minimum 3 reviewers) followed by a visit which could take 3-5 days. The site visit allows the reviewers to verify the submitted data and information and closely observe the services and infrastructure or what could not be documented. The reviewers develop their report draft and send it to the institution for further comments and feedback. Finally, a decision will be issued by NAQAAE on the eligibility of the institution for accreditation. The institution could be accredited successfully, not accredited or the accreditation will be postponed until all standards of accreditation are fulfilled (NAQAAE 2015, pp. 17-21).

Since 2007 NAQAAE has conducted several institutional and programs audits and accreditation. According to the activities reported on NAQAAE's website until up 2018 (see https://admin.naqaae.eg/api/v1/archive/download/4633), the number of audits of pre university educational institutions reached 8379 visits (which forms $13 \%$ of total number of these institutions), and the number of audits conducted on higher education institutions reached 447 visits. Moreover, $6.5 \%$ of pre university education is currently accredited and 19\% of higher education institutions have obtained institutional accreditation.

The exemplary effect of NAQAAE has been reflected remarkably in the performance of the programs and institutions been accredited. To demonstrate the impact of this national accreditation, the example of Menoufia Faculty of Medicine will be presented. The information was provided through interview with Professor Dr. Wafaa Ahmed Zahran, Dean of Faculty of Pharmacy and Director of Quality Assurance Center at University of Menoufia on October 16, 2019. The Faculty of Medicine at University of Menoufia was accredited by NAQAAE in 2013 and the accreditation certificate was renewed in 2019.

The national accreditation has made a significant impact on the development of the Faculty of Medicine at University of Menoufia in a variety of aspects. First, in order to safeguard the quality of education outcomes, the faculty has planned to pay attention to the quality of inputs and elements of the education process which comprise human resources, environment and students. Part of the plan includes training teaching staff about best practices in, e.g., teaching, curriculum design and assessment in the field of medicine, increasing lecturing halls and labs and equipping them with advanced learning tools, and 
enhancing the concept of quality assurance among students through workshops, periodic meetings and annual students' conferences that focus on significance of quality assurance and accreditation.

Second, as a result of the efficiency of the education process following the accreditation, student satisfaction about the quality of education process at the faculty has improved considerably. This is well represented in the positive results of the students' surveys run at the faculty as reported by the director of Quality Assurance. Third, the Faculty started to involve external stakeholders, such as employers, customers, and alumni in planning the learning programs and teaching strategies through inviting them to meetings of main committees and councils, such as the administrative councils of the quality assurance unit and hospitals. Forth, more attention was paid to enhancement of the culture of quality among teaching staff and administrative staff through periodical meetings, seminars, and posters. Finally, constant development and improvement has been included in the strategic planning of the faculty. This included establishment of the Education Development Center which enhances electronic education, research productivity, modern teaching methods and academic training on teaching for learning, assessment in medical education, curriculum development, problem based learning, open learning website and applications, and introduction to HR (for further details on the Faculty see http://mu.menofia.edu.eg/med/View/2709/en). For a comprehensive analysis of the Egyptian accreditation system and role of NAQAAE, interested readers are referred to Schomaker (2015).

\section{Blended Education in Egypt}

Following the lockdown imposed by COVID19 in 2020, the education sector in Egypt had to respond with an alternative mechanism to meet the needs of students and redeem the education process. For this purpose, the education system in Egypt introduced the blended education where online and campus-based teaching and learning merge. This process is effective in several aspects, such as decreasing the crowd of students at campuses, enabling students to be more independent learners, and more involving technology in education. Transferring to a blended or online education was not smooth and straightforward in Egypt, as was the case in many other Arab countries, due to lack of any previous similar experience.

In order to implement the online process as part of the blended education, several preparations have taken place. These included (a) providing an applicable learning management system; (b) ensuring the availability of technological infrastructure such as internet services through coordination with the Ministry of Communication; and (c) organizing several online trainings and workshops to introduce the online education to staff and students and learn about the online platforms. In addition, academic and technical support was provided to students to guide them throughout the process and achieve the intended objectives.

Part of the blended education required dividing up students into small manageable groups and assigning different working days in the week for the groups. Moreover, the Supreme Council of Universities (SCU) proposed \%60-70 campus-based teaching and \%30-40 online teaching for practically oriented specializations, and \%50-60 campus-based and \%40-50 online for theoretical and humanitarian fields.

Assessing the quality of the blended education requires a somehow different set of criteria as part of the quality assurance process. Among the criteria considered by NAQAAE are the technological infrastructure of the institution, the learning management system, academic and technical support of students, teaching 
staff trainings and online assessments. More specifically, the basic components of assuring the quality of blended education requires achieving the same aimed quality achieved in time of traditional education. Thus, it requires the existence of a robust policy that defines the learning objectives and learning outcomes within such framework. Moreover, defined policies and standards for online education will help identifying the roles and responsibilities of the teacher, student, and the online platform.

As a developing country, transferring to a blended education that involves online teaching was not free of challenges in Egypt. Among the major challenges were poor internet penetration and lack of technological skills of teaching staff. Moreover, designing effective assessment tools and examinations was another problematic issue to consider in obtaining the right evaluation of students' performance. Also, many families could not afford the internet services costs required to run the learning management system. Solutions to handle some of these difficulties have been considered by the government and Ministry of Higher Education.

In an attempt to guarantee the success and efficiency of the blended education, the process has been examined at University of Menoufia against a set of indicators such as staff and students' satisfaction about the teaching and learning process, numbers and types of trainings offered to staff, staff workload, and frequency of staff-students communication. This information has been collected through a number of questionnaires and surveys distributed among staff, students and top management at the University. The recommendations included the necessity of appropriately mapping learning objectives to program learning outcomes, the existence of policies and instructions that assure the accessibility and quality of the online materials, providing a securing electronic management system that protects its users, clarity and objectivity of the assessment process by implementing a variety of applicable tools such as exams, online presentation, individual and group projects or other assignments, and providing all relevant and necessary reference and learning guide (email communication with Dr. Wafaa Ahmed Zahran, Dean of Faculty of Pharmacy and Director of Quality Assurance Center at University of Menoufia on March 29, 2021).

According to plans of Ministry of Higher Education, the blended education is planned to continue for 2020-2021 until normal education becomes a possible option. Moreover, the Ministry of Higher Education and Ministry of Communication and Information Technology in Egypt are planning to further develop the technological infrastructure of its universities by adopting electronic examination system and digitalizing the learning contents and management systems as part of their plan to transfer universities into more online-based ones (see http://portal.mohesr.gov.eg/ar-eg/Pages/dtu_projects.aspx).

\section{Conclusion}

In this paper the history, structure and characteristics of the higher education and quality assurance system in Egypt have been reviewed. The review shows a very long-standing and intriguing history of higher education that goes back to 5000 years ago when 'Oan' (Sun/Heliopolis) University was established. Today, there are around 264 higher education institutions that offer post university degrees in Egypt. The start of the internal quality assurance system was initiated with the National Conference for Higher Education in 2000. Moreover, Egypt is among a very few Arab countries that grants national accreditation through its licensed agency, the National Agency of Quality Assurance and Accreditation of Education (NAQAAE), established in 2006. Since then, 19\% of higher education institutions located in Egypt have 
been nationally accredited. NAQAAE has had evident impact on the academic performance of the staff, programs progress and institutions growth and recognition.

Moreover, the Egyptian government resorted to the blended education to continue the education process during COVID19. Despite the preparation made for this purpose in terms of the learning management system and trainings, financial support and effective assessment tools should be attentively considered. Finally, in the face of the various political, social, and economic unstable periods and challenges in the history of Egypt, Egyptian higher education has proven to be among the fast-growing systems in the Middle East. More resources and financial support are certainly required to be allocated by the authorities in the Egyptian government for internationalization purposes.

\section{References}

Buckner, E. (2013). Access to higher education in Egypt: Examining trends by university sector, Comparative Education Review, 57(3), 527-552.

Emira, M. (2014). Higher education in Egypt since World War II: Development and challenges. Italian Journal of Sociology of Education, 6(2), 8-35.

Farag, I. (2007). Egypt. In J. J. F. Forest and P. G. Altbach (eds) International handbook of higher education, part one: Global themes and contemporary challenges. Dordrecht: Springer. 693709.

Ibarra, G. L., Sinha, N., Fayez, R., \& Jellema, J. (2019). Impact of fiscal policy on inequality and poverty in the Arab republic of Egypt. Policy Research Working Paper, 8824, 1-39.

Ministry of Higher Education. Official Site. Retrieved from http://portal.mohesr.gov.eg/areg/Pages/default.aspx

NAQAAE, (2015). The accreditation guideline of colleges and institutes in higher education. 3rd ed. (available in Arabic).

OECD/The World Bank. 2010. Reviews of national policies for education: Higher education in Egypt. Paris: OECD Publishing. https://doi.org/10.1787/9789264084346-en.

Radwan, M. M. (2016). Arab Republic of Egypt. In Y. M. Lai, A. Ahmad and C. da Wan (eds), Higher education in the Middle East and North Africa: Exploring regional and country specific potentials. Singapore: Springer. 11-40.

Ramadan, F. I., Zaaba, Z., \& Umemoto, K. (2011). Quality assurance of Egyptian higher education: A policy transfer. Literacy Information and Computer Education Journal, 2(1), 338-349.

Reid, D. M. (1990). Cairo University and the making of modern Egypt. Cambridge: Cambridge University Press.

Richards, A. (1992). Higher education in Egypt. The Policy Research Dissemination Center.

Schomaker, R. (2015). Accreditation and quality assurance in the Egyptian higher education system, Quality Assurance in Education, 23(2), 149-165.

Shann, M. H. (1992). The reform of higher education in Egypt. Higher Education, 24(2), 225-246.

The National Quality Assurance and Accreditation Committee and the British Consultants in Higher Education (2004). The quality assurance and accreditation handbook for higher education in Egypt. Giza: Ministry of Higher Education and HEEP. 